\title{
La Constitucionalización del Derecho y la Interpretación Jurídico \\ Constitucional
}

\section{The constitutionalization of law and the constitutional-juridical interpretation}

SONIA PATRICIA CORTÉS ZAMBRANO.
${ }^{1}$ Docente Investigadora del Centro de Investigaciones Socio Jurídicas Francisco de Vitoria de la Universidad Santo Tomás. Abogada de la Universidad Santo Tomás, Especialista en Derecho Constitucional y Derecho Parlamentario de la Universidad Externado de Colombia y Universidad Autónoma de Madrid España, Magíster en Derecho Público Universidad Santo Tomas y Universidad de Konstanz Alemania, Doctoranda en Derecho de la Universidad Externado de Colombia.Correo Electrónico:: sonetzka@hotmail.com, soniacortes@usantotomas.edu.co

Professor and investigator from the Socio-Juridical investigation centre Francsico de Vitoria from the Santo Tomas University. Attorney at law of the Santo Tomas

University, Specialist in Constitutional Law and Parliamentary Law from the Exterando University of Colombia and the Autonoma University of Madrid, Spain, Master in Public Law from the Santo Tomas University and the Konstanz University, Germany, Doctor in Law from the Externado University in Colombia. E-mail: sonetzka@hotmail.com, soniacortes@usantotomas.edu.co

Fecha de recepción: 1 de abril de 2011 Fecha de evaluación: 11 de abril de 2011 Fecha de aprobación: 14 de abril de 2011

RESUMEN: El presente documento es una reflexión académica frente al tema de la Constitucionalización del derecho y el impacto de éste fenómeno en los procesos de interpretación del derecho, la seguridad jurídica y el poder discrecional de los jueces a la luz de las principales ideas de la doctrina constitucional europea y colombiana. La doctrina jurídica constitucional se va construyendo a partir de la ejercicio o práctica jurídica, debe mirarse lo que hacen 
los juristas y a partir de la observación deducir los conceptos generales de derecho; es así como el ejercicio epistemológico ordena las experiencias generando el conocimiento. Se busca adelantar un recorrido por las características fundamentales del neoconstitucionalismo, sus críticas a favor y en contra y contrastarlo desde el punto de vista jurídico con el nuevo ejercicio o praxis constitucional en Colombia, como respuesta a las exigencias de la evolución progresista del pensamiento jurídico.

PALABRAS CLAVES: Neoconstitucionalismo, Interpretación Constitucional, Constitución Política, Seguridad Jurídica.

SUMARY: This document is an academic reflection towards the theme of constitutionalization of law and the impact of this phenomenon in the process of statutory interpretation, legal certainty and discretional power of judges in light of the main ideas of constitutional doctrine European and Colombian. The constitutional jurisprudence is built from the exercise or practice of law, must look what the legal basis of observation and deduction of the general concepts of law, and the exercise is directed epistemological knowledge generating experiences. It seeks to advance a tour of the basic features of neoconstitutionalism, his criticisms for and against and to contrast it from the legal point of view with the new 
constitutional exercise or practice in Colombia, in response to the demands of the progressive evolution of legal thinking.

KEY WORDS: Neoconstitutionalism, discresional power of judges, Constitutional Interpretation, Constitution, Legal Security.

Identificación del Artículo: Reflexión Académica.

\section{LA CONSTITUCIONALIZACIÓN DEL DERECHO Y LA INTERPRETACIÓN JURÍDICO CONSTITUCIONAL}

Las exigencias de la evolución y transformación social, requieren de un replanteamiento concreto y unificado, que permita que los postulados constitucionales sean una realidad, realidad frente a la cual los ciudadanos de cada nación, vean garantizados su dignidad y sus derechos fundamentales.

La doctrina jurídica se va construyendo a partir de la práctica jurídica, según kelsen, debe mirarse lo que hacen los juristas y a partir de la observación deducir los conceptos generales de derecho; se ordenan las experiencias generando el 
conocimiento, nos encontramos con un nuevo concepto que ha sido ampliamente debatido y destacamos algunos de los puntos más relevantes de la discusión.

No existe consenso hay muchas versiones que difieren las características propias del Neoconstitucionalismo y partiremos de las más comunes. Se pretende comprender y evaluar los elementos esenciales del constitucionalismo contemporáneo, analizar su incidencia en la transformación del derecho desde el iusnaturalismo y el iuspositivismo y la importancia que toma a partir de éste hecho la teoría de la Argumentación.

Demos una mirada rápida a las líneas del pensamiento jurídico en torno a tema de la validez del derecho y cual es a partir de su definición la relación con la evolución de constitucionalismo, que hoy hace depender la validez del derecho entre otras exigencias a su constitucionalidad, es decir una ley es válida si es emitida por autoridad competente, respetando los procedimientos señalados en la constitución y la ley, respetando el ordenamiento jurídico y el principio de supremacía de la Constitución. Veamos:

\section{IUSNATURALISMO.}

Iusnaturalismo Clásico: Regla de Validez: Leyes de la naturaleza, todo derecho para que sea aplicable debe obedecer a las leyes de la naturaleza. (Aristóteles) 
lusnaturalismo Medieval: Regla de Validez: Leyes Divinas, la divinidad, Dios. Para que el derecho sea aplicable debe obedecer a las leyes divinas. (Santo Tomás)

Iusnaturalismo Racionalista: Centro del Mundo el Hombre, Regla de validez, el Humanismo. Para que el derecho pueda ser aplicable debe obedecer a la razón, ser el resultado de un ejercicio razonable cuyo eje es el hombre. (J. Bentham)

\section{POSITIVISMO ESTÁTICO:}

Formalistas: El derecho es válido solo si lo emite el órgano del Estado competente, atendiendo a los procedimientos establecidos para ello. Las Normas son formas no valores. La interpretación se hace por subsunción (aplicación del derecho a hechos concretos acomodar el hecho al contenido de la norma). La realidad que es cambiante no entra en el cambio de la norma. El operador jurídico no crea derecho, solo es la boca de la ley. Su objetivo es la seguridad jurídica. (Kelsen, Hart)

Normativistas: Atienden al postulado formalista, pero agregan el deber respetar el Sistema Normativo. El derecho es válido solo en tanto que lo emita autoridad competente, regido por un procedimiento y respetando el Sistema Normativo. 
Los Normativistas:

1. Separan estrictamente el Derecho de la Política.

2. Separación entre SER: Realidad y Deber Ser: Derecho.

3. Separación entre el Derecho y la Sociología

4. Separación entre Derecho y Moral

Kelsen en su teoría pura del Derecho, señala que la eficacia del derecho es condición para su validez, pero no la razón de ella, por eso no es su fundamento. Un orden jurídico no pierde su validez aún si es ineficaz, la norma sigue siendo derecho, así la realidad cambie el derecho sigue siendo el mismo.

\section{POSITIVISMO DINÁMICO}

Permite conexión entre ser y deber ser, el derecho cambia y fluctúa de acuerdo a la realidad.

Positivismo Axiológico: Relación entre Derecho y Moral, conexión Con valores éticos y políticos. Principios (Dworkin), Valores (Alexy). Cuando las Constituciones irradian todo el ordenamiento, estamos ante un positivismo axiológico pues éstas están conformadas por principios y valores. Los derechos fundamentales son principios. 
Principios: Norma abstracta cerrada, concreta: Igualdad ante la ley

Valores: Normas Abiertas: igualdad

Reglas: Supuesto de hecho y supuesto de derecho, que relacionados definen el caso. Ley de cuotas $30 \%$ de mujeres en todos los cargos.

El contenido de la igualdad lo da la moral, por eso la unión se da a partir de principios y valores. Surgen entonces las técnicas de argumentación que sustentan el Derecho.

Entonces el derecho es válido, en el positivismo dinámico, si es generado por el órgano competente, respetando el procedimiento establecido, de acuerdo a la jerarquía de las normas y si es moralmente correcto.

\section{POSITIVISMO QUE ATIENDE A LA REALIDAD}

Ataca el positivismo normativista, conecta el derecho con la sociología, se da la conexión entre el Derecho y la Realidad, presentan el texto escrito en conexión con la realidad. 
Dos características del Derecho: su permanencia en el tiempo y su cambio, debido al cambio en las relaciones sociales, es un derecho hecho por hombres y para hombres, no puede aislarse de la realidad.(Hesse, Müller, Häberle)

Si tenemos una Constitución de normas abiertas que ilumina todo el ordenamiento jurídico, la realidad trabaja en armonía con el Derecho.

Toda norma Constitucional tiene:

Programa Normativo: lo que la disposición constitucional dice, es la expresión lingüística y literal.

Ámbito Normativo: que constituye la realidad constitucional, lo que la hace móvil a la realidad.

Para ésta corriente la Validez del Derecho descansa en que sea emitido por órgano competente, por los procedimientos establecidos, respetando el sistema normativo y acorde con la realidad constitucional existente.

Partiendo de lo expuesto la relación consiste en que, el ordenamiento jurídico para ser válido debe en su totalidad respetar la Constitución, que la creación de toda norma jurídica debe atender al principio de constitucionalidad de la ley y que la 
interpretación del ordenamiento jurídico debe realizarse a la luz de las disposiciones constitucionales.

Teniendo la Constitución Política de 1991, características como valor normativo: carácter vinculante que obliga a su cumplimiento a través de acciones consagradas en su texto, con la existencia de un tribunal (Corte Constitucional) que se encargue de velar por su salvaguarda, su carácter valorativo: conjunto de valores y principios y su carácter abierto (Unprinmy 2004 ), constituye en sí misma un apartado de consideración especial a la hora de su interpretación, además como irradia todo el ordenamiento jurídico, éste también se sujeta a las mismas reglas de interpretación, que hoy en tiempos del llamado neoconstitucionalismo, exige el desarrollo y la comprensión de la llamada teoría de la argumentación y su implicación en la seguridad jurídica.

Desde el punto de vista jurídico, la redacción de la Constitución Política de Colombia de 1991, respondió a las expectativas generadas por el llamado constitucionalismo moderno, que tiene su expresión en el Estado Constitucional. Dentro de los rasgos más sobresalientes de éste modelo de Estado, encontramos:

1. La difusión de las constituciones rígidas, que como lo expresa (Guastini 2003), son escritas, protegidas y garantizadas contra la legislación ordinaria, en la medida en que las normas constitucionales no pueden ser derogadas, modificadas o abrogadas, si no es mediante un procedimiento 
especial, destacándose la supremacía de la constitución, en el ordenamiento jurídico.

2. La naturaleza normativa de la Constitución, de la cual se desprende el concepto de constitución como norma jurídica y la eficacia jurídica de la constitución, son enfoques que obedecen a que la Constitución se encuentra llamada a producir en todo momento efectos jurídicos, tiene aplicación directa y tiene un papel de límite a la producción legislativa en el Estado constitucional.

3. Se redefine la naturaleza jurídica del Estado, aparece el concepto de Estado social de Derecho, que pretende el bienestar general de la sociedad incorporando un catálogo de derechos fundamentales, sociales, económicos y culturales, que son los que le otorgan la fuerza vinculante a la constitución, además se consagran disposiciones que regulan directamente las relaciones entre el Estado y los ciudadanos. La constitución consagra derechos de libertad para los ciudadanos, principios generales y disposiciones programáticas. Los primeros claros y precisos, los segundos que requieren de una interpretación y aplicación por parte de jueces, órganos del Estado, Legisladores.

4. La justicia constitucional, ya no solo salvaguarda la supremacía de la Constitución, sino que ostenta el poder de ser el garante de la realización material de la constitución. En Colombia la Corte Constitucional, traduce su papel en la elaboración de sentencias de constitucionalidad, sentencias de inconstitucionalidad y sentencias de tutela. 
5. La Interpretación Constitucional, y la importancia creciente de la teoría de la argumentación ha constituido un punto crucial en las discusiones. El ordenamiento jurídico es un sistema, cuyos elementos integrantes no pueden ser vistos aisladamente, sino como parte de un gran todo (interpretación sistemática). (Savigny 2004) en su exposición de criterio sistemático de interpretación, señala que existe una conexidad material en todo el ordenamiento legal, y por ello el intérprete debe configurarlo armónica y razonadamente. Sin embargo la doctrina complementa el método de interpretación acudiendo a los argumentos a coherencia, que armonizan las disposiciones encontradas. La argumentación juega un papel crucial al momento de interpretar, y dentro de los modos de argumentar se encuentra la Ponderación, dirigida especialmente a la interpretación de principios o derechos fundamentales encontrados, y se acude al test 0 juicios de proporcionalidad, y test o juicios de razonabilidad. Se toma conciencia del carácter complejo de la interpretación constitucional, que como lo expresa (Bernal 2005), "depara al interprete un irreducible margen de discrecionalidad, en el que tienen cabida su ideología, sus inclinaciones políticas, por no mencionar las emanaciones inconcientes de su perfil psicológico y las demás improntas subjetivas."

La evolución del constitucionalismo ha llevado a una crisis en el modelo del Estado Constitucional en la medida en que se ha generado gradualmente un papel creativo de la jurisdicción, (pasos hacia un derecho jurisprudencial), y una pérdida 
de la unidad y coherencia de las fuentes de convivencia y superposición de diversos ordenamientos concurrentes. (Ferrajoli 2003).

Se evidencia un problema que nace y crece a la par con la evolución del constitucionalismo, la actividad política que supedita la legislación a la administración. Cada ley que pretende nacer a la vida jurídica, y cada búsqueda de una reforma constitucional, surge de un interés político, temporal, que sin duda se mantiene como eje generador de nuevas crisis, afectándose con ello el principio de legalidad, dando lugar, como bien lo expresa Ferrajoli, a una inflación Legislativa, y una disfunción del lenguaje legal. Estas leyes nacen todos los días en lenguajes oscuros dando paso a confusiones normativas, abriendo la posibilidad a la discrecionalidad ilimitada de los jueces, y a la formación jurisprudencial del derecho perdiendo certeza, eficiencia y su carácter garantista. El principio de legalidad propio del estado de Derecho empieza a perder sentido, se genera incertidumbre a nivel de competencias, y se da curso al nuevo derecho jurisprudencial.

Al parecer, el juez ya no solo aplica el derecho existente, sino que se configura en creador de nuevo derecho en sus decisiones, y esto es claro cuando se sabe que el intérprete nunca renuncia a introducir en sus sentencias sus concepciones propias de justicia y política. Esto ocurre frente a la indeterminación de la norma, y debemos conformarnos con que el juez decide no lo que el derecho debe ser sino lo que el derecho es, según la interpretación general de la constitución. 
(Comanducci 2003), en algunas de sus reflexiones, presenta el Neoconstitucionalismo desde tres perspectivas a saber: Neoconstitucionalismo como ideología, como teoría, y como método. Rápidamente, señala el autor que el neoconstitucionalismo ideológico, no se limita a describir los logros del proceso de constitucionalización, sino que los valora positivamente y propugna su defensa y ampliación. A su vez señala Críticamente: "La disminución del grado de certeza del derecho, se deriva de la técnica de ponderación de los principios constitucionales y de la interpretación moral de la constitución."

Por su parte, la concepción teórica del neoconstitucionalismo, apunta según el autor, al "modelo constitucional es decir: el conjunto de mecanismos normativos e institucionales realizados en un sistema jurídico político, históricamente determinado, que limita los poderes del Estado y/o protegen los derechos fundamentales."

Finalmente el neoconstitucionalismo metodológico, presenta la tesis de la conexión necesaria, identificativa y/o justificativa, entre derecho y moral (Comanducci 2003).

¿Contribuiría entonces el Neoconstitucionalismo a la indeterminación del derecho?, ¿qué tan importante es el papel de la certeza del derecho en 
contraposición con el valor de la autonomía personal, el ejercicio de la razón, la moral, y la voluntad, a la par de la función de la argumentación jurídica?

Por su parte (Prieto 2003), advierte que una de las ideologías del neoconstitucionalismo se identifica con la filosofía política que considera el Estado Constitucional de Derecho, la mejor y más justa forma de organización política, objetando la supremacía del legislador o su carácter superior frente al estado democrático y presenta como una de las consecuencias de la ponderación judicial la reducción de las esferas de decisión de las mayorías parlamentarias. Ya no encarna la ley la suprema fuente de derecho, lo cual cerca la teoría del derecho positivista, que se nutrió por años de los dogmas de estatalizad y legalidad del derecho. Así el Neoconstitucionalismo, trae consigo la necesidad de creación de nuevos enunciados epistemológicos, que funden una nueva teoría del derecho que, entreguen a la comunidad jurídica claridad frente a conceptos como: Principios, Ponderación, transversalidad del derecho constitucional, discrecionalidad de los jueces y homogeneidad ideológica.

Frente a la propuesta de una Nueva teoría del derecho (García 2003), cita a filósofos del derecho con vocación de constitucionalistas y de constitucionalistas con vocación de filósofos del derecho, como Alexy, Ferrajoli, Dworkin, Coleman, walluchov, Peces Barba y Zagrebelsky, para sustentar la idea de la "desfiguración de la contraposición entre lusnaturalismo y Positivismo. Una nueva tendencia hacia un neorrealismo y cierto neoiusnaturalismo. Explica el autor, que el 
neoiusnaturalismo hace presencia a partir de la proposición de R. Alexy, frente a un positivismo jurídico Hartiano debilitado por los postulados de R. Dworkin, cuyo punto de encuentro se da en el proceso de contitucionalización de los ordenamientos jurídicos.

La explicación conduce a la siguiente tesis: si existen principios en el derecho, entonces el positivismo jurídico resulta inviable, los principios albergan en sí un contenido moral, que repercute sobre el resto del ordenamiento jurídico. (Figueroa 2003).

Debe tenerse en cuenta que el constitucionalismo contemporáneo responde a las nuevas tendencias de cambio social y político de los pueblos, el multiculturalismo, las relaciones existentes entre sociedades abiertas y plurales, situaciones que reclaman respuestas acordes a los cambios y necesidades de las nuevas sociedades, y así lo expresa (Zagrebelsky 2002), al afirmar que en la actualidad asistimos a una relativización de la noción de soberanía y fenómenos como el multiculturalismo que reclaman normas adecuadas para las transacciones y argumentaciones ante las relaciones sociales contemporáneas.

\section{CARACTERÍSTICAS DEL NEOCONSTITUCIONALISMO}

En síntesis lo expuesto se concreta en las siguientes ideas: 
- La Constitución no es solo formal sino también material, ya no es solo una fórmula de reparto de poderes, sino que comprende la institucionalización de unos valores como principios, disposiciones, derechos fundamentales. Es garantizada materialmente, es exigible jurídicamente no solo a través de La Corte Constitucional, sino también a través de los jueces ordinarios, que se convierten en jueces constitucionales.

- La ley solo tiene validez cuando se encuentre ajustada a la Constitución, toda ley debe ser constitucional.

- Se habla de la transversalidad del Derecho Constitucional, la ley se ajusta al contenido de los derechos fundamentales, sus contenidos irradian sus efectos a las leyes civiles.

- Si existen principios en el derecho, entonces el positivismo jurídico resulta inviable, los principios albergan en sí un contenido moral, que repercute sobre el resto del ordenamiento jurídico.

- La ponderación, o principio de justa ponderación como dirían los juristas alemanes, y el principio de proporcionalidad para la aplicación de los principio fundamentales.

\section{CRITICAS}

1. Cuando la constitución se materializa, se institucionalizan unos valores que en la sociedad no gozan de consenso por ejemplo el alcance de la definición humana. Existe la imposibilidad de encontrar un contenido 
objetivo de cara a la epistemología de las disposiciones constitucionales, las hace inaplicables. (Juan Antonio García Amado)

2. Al no existir certeza en el contenido de los valores entonces el juez no está preparado o legitimado para aplicar la constitución. Es el juez quien impone sus concepciones ideológicas al decidir, cuando el significado que se determina del contenido de una disposición constitucional es altamente indeterminado, lo cual ofrece un espacio amplio para el ejercicio de la discrecionalidad del intérprete, el juez impone sus concepciones ideológicas al decidir.

3. Si se habla de un desvanecimiento de la barrera entre ley y constitución, no estaríamos ante una violación del poder democrático, el legislador reduce ostensiblemente el margen de acción para decidir, el legislador democrático sujeta sus decisiones a la fuerza de la constitución que limita la legitimidad del legislador para legislar.

4. No es claro que exista diferencia entre reglas y principios (MORESO 2003), es igual aplicar una regla de un código a una disposición constitucional indeterminada, un principio.

5. La Ponderación es irracional, implica la comparación de dos cosas diferentes en esencia, incomparables entre si, la decisión basada en la ponderación enmascara la subjetividad del juez (GARCIA 2003).

\section{POSTULADOS A FAVOR}


1. La ponderación es racional, es un proceso de construcción racional. Es un racionamiento, que consiste en reducir las comparaciones a una escala, y aunque ciertamente de lugar a un margen de subjetividad, es un ejercicio racional que argumenta y justifica la decisión.

2. Siendo la ponderación un ejercicio racional, se configura como un criterio serio de aplicación de normas jurídicas. Se diferencia claramente regla de principio, a partir de la subsunción se aplican reglas y de la ponderación, principios.

3. El ámbito del legislador democrático no se limita por el control de constitucionalidad de la ley. Dentro del marco constitucional se encuentra la libertad de configuración legislativa. El legislador conserva un margen de acción sujeta a la constitución, como protección a los intereses sociales y de la comunidad ciudadana, las personas.

4. Debe tenerse en cuenta que pretender el objetivismo es irracional, no existe el juicio objetivo, siempre se está en presencia de un margen de subjetividad, se deben conocerlos límites de la racionalidad humana no reconocerlo es irracional. Si no hay una acertada decisión no significa que el modelo esté errado o sea inoperante, por eso deben formarse los operadores jurídicos, debe buscarse la coherencia en la práctica jurídica, y enseñarse las normas de argumentación jurídica.

El autor alemán (Schmitt 1983), Presagió que la jurisdicción constitucional, llevaría inexorablemente al gobierno de los jueces, y se ha podido constatar en 
nuestro país la judicialización de la política, decisiones políticas que emanan de la Corte Constitucional, decisiones que adoptan cubriendo el cumplimiento de los postulados de la constitución colombiana que el propio estado no puede cubrir, generándose el llamado activismo judicial.

Pese a los innegables procesos de evolución constitucional plasmados en el modelo de Estado Constitucional, se evidencia que el proceso evolutivo continúa, y que en un primer momento se presenta como una de las consecuencias de este proceso de cambio, el debilitamiento del principio de seguridad jurídica y certeza del derecho. Esta vulneración, se sustenta inicialmente en la controvertida usurpación de competencias: choque de trenes, seguido de las decisiones muchas veces contrapuestas emanadas tanto de la Corte Constitucional como de las diversas jerarquías judiciales.

El principio de seguridad jurídica encuentra sustento en conceptos como: cosa juzgada, sentencia en firme, certeza del derecho y la interpretación uniforme, pero como Hart señala, la existencia de de una única respuesta correcta que excluye la posibilidad de discreción judicial es un "noble sueño". Frente al tema (López 2000), advierte que luego de más de 20 años de sentencias constitucionales, debe tenerse en cuenta la importancia del precedente constitucional y revalorar la actividad del juez constitucional, a partir del estudio de la jurisprudencia constitucional como fuente de derecho, lo cual constituye una vía que le devuelve al derecho constitucional su credibilidad. 
Sintetizando, dentro de las características del Neoconstitucionalismo, encontramos: omnipresencia del derecho constitucional, todo es constitucionalizado, generación del poder absoluto de los jueces, surgimiento del problema del estado de cosas inconstitucional, mengua de la autonomía del legislador, y por ultimo la falta de homogeneidad en la ideología del texto constitucional, que debe ser armonizada en el proceso de interpretación.

Sin embargo, no debe olvidarse que la independencia judicial, es un principio axial del Estado de Derecho, y se funda a su vez en los principios de la libre interpretación de la ley por el Juez y la capacidad de éste igualmente de valorar libremente el material probatorio. El proceso decisional de los jueces, ocasionalmente, puede convertirse en ropaje de la arbitrariedad o sin razón si lo separamos del ejercicio racional de la justa ponderación. Algunos atacan el proceso evolutivo hacia el neoconstitucionalismo, basados en que el derecho esta precisamente llamado a generar certidumbre y seguridad jurídica, pero no debe adoptarse una posición en mi concepto tan radical. La visión positiva de ésta evolución, es que los cambios son naturales y la ciencia jurídica debe adaptarse a estos cambios que no son inadecuados, precisamente por ser naturales. Como bien lo sostienen algunos autores, estamos frente a una forma contemporánea de iusnaturalismo, que nos exige confianza en la discrecionalidad de los jueces. Es innegable que el poder de los jueces avanza y se fortalece, que sus decisiones abarcan incluso fronteras políticas, pero es innegable que el modelo de Estado Social de Derecho, planteado en la constitución exige eficiencia y efectividad, que 
no se alcanzan en muchas ocasiones a través del ejercicio del gobierno y el congreso, problema que asume hoy por hoy la rama judicial.

La antigua idea de justicia de dar a todos por igual lo que les pertenece, resulta ahora sustituida por la argumentación racional que ofrezca el juez en su sentencia y por el derecho de éste a apartarse de posiciones anteriores, siempre y cuando ofrezcan razones serias para ello.

Si bien es cierto que con la adopción de la constitución política de 1991 en Colombia se establece el tribunal constitucional (Corte Constitucional), no quiere esto decir que en Colombia se acogiera el sistema de control concentrado, en nuestro sistema ejercen control constitucional, no solo la corte, sino además cualquier juez y los órganos de la rama judicial. (Morelli P. 10).

El nuevo rol de la Corte constitucional en Colombia y varios países de occidente, sin duda ha generado una problemática en cuanto a la separación de los poderes, toda vez que "no solo aplican derecho a un caso concreto, como ordinario corresponde al juzgador. En realidad, las cortes constitucionales, con ocasión del control de constitucionalidad, también crean derecho, que obliga incluso al legislador" ( Morelli p. 11), existe por tanto interacción entre la Corte y el legislador en cuanto a decisiones políticas y jurisdiccionales. 
Al tener la Corte Constitucional la función de revisión eventual frente a las tutelas, agravo el conflicto entre las altas Cortes( Corte Suprema de Justicia, y Consejo de Estado), toda vez que estas pasaban, en algún sentido, a ser instancias respecto a la Corte Constitucional, éste fenómeno traería consigo un peligro al principio de seguridad jurídica, ya que los jueces por medio de la tutela estarían facultados para apartarse de las decisiones de órganos superiores.

Es la corte Legislador negativo y en algunos casos Positivo (Morelli P.38), existe una diferencia clara entre norma y disposición, la primera se refiere a la interpretación que se hace de la segunda, que es simplemente la literalidad, el texto escrito. A causa de esto de una disposición pueden salir varias normas y de muchas disposiciones puede salir una norma, la Corte Constitucional se pronuncia, solo si existe plena coincidencia entre norma y disposición, pero dicha situación ha cambiado, producto del derecho viviente donde se plantea que es la norma la que debe ser interpretada, permitiendo que el órgano declare inconstitucional la disposición y asuma como vigente la norma.

La Corte Constitucional actúa como legislador positivo en virtud a las sentencias interpretativas, que en ocasiones alteran el querer del legislador.

Respecto a si la sentencia es fuente de derecho, no existe discusión en el tema de la parte resolutiva respecto a su poder vinculante, hablando sobre las sentencias de control de constitucionalidad, por ser erga omnes, caso contrario de las de 
tutela que son inter partes; el problema radica en la parte motiva, si es o no fuente de derecho. El problema se soluciona, dándole el carácter de fuente de derecho también a la parte motiva debido a su carácter interpretativo, ya que da cuenta del porqué de la decisión. Tendría entonces que ubicarse en la jerarquía de las normas y esto se hace equiparándola a la ley. (Morelli, 1997)

Se deriva de la actividad de la Corte Constitucional el llamado activismo constitucional, generado a su vez por la doble vinculación de los jueces a la ley y a la Constitución, por tanto los jueces imparten justicia aplicando el Derecho vigente desde la perspectiva moderna, propia de un Estado constitucional de derecho que supone su doble sumisión a la Constitución y a la ley.

La ley, cede el paso a la Constitución y se convierte en ella misma en objeto de medición y esta instancia más alta asume ahora la importantísima función de mantener unidad y en paz de sociedades enteras divididas en su interior y concurrencia les. Una función inexistente en otro tiempo, cuando la sociedad política estaba, y se presuponía que era en si misma, unidad y pacífica. En la nueva situación, del principio de constitucionalidad es el que debe asegura la consecución de este objetivo de unidad (Zagrebelzky, 2002)

La Constitución es norma jurídica que vincula a todos los poderes del Estado y a los particulares. De esta manera la Constitución ya no es solo fuente de derecho sino fuente inmediata de derecho o de aplicación directa. 
Según (Aragón 1997) lo anterior produce los siguientes efectos: Se da una ampliación a la Constitución de tal manera que el ordenamiento jurídico debe ser estudiado y analizado a la luz de la Constitución, por lo tanto entre o tras las funciones del tribunal constitucional serían declaran la inaplicación de la ley por considerarla incompatible o contraria a la constitución, excluyendo esta posibilidad para los jueces ordinarios quienes continuaban sujetos al imperio de la ley.

En materia de derechos fundamentales, corresponde esencialmente a la ley, el desarrollo de las reglas y principios constitucionales. La Constitución asegura, frente al pluralismo solo su contenido esencial pero no el completo y detallado régimen del ejercicio de cada derecho, corresponde entonces constitucionalmente al legislador desarrollar, concretar los derechos fundamentales (Aragón 1997). Puede entonces deducirse que le atañe solo a la Corte Constitucional, definir el contenido de los derechos fundamentales, y ser el ente unificador de la doctrina constitucional, se conforma así la Corte como el supremo intérprete de la Constitución.

Como señala (Bernal 2005): "Desde esta perspectiva, el margen de discrecionalidad que la interpretación de los derechos fundamentales atribuye a la Corte, se perfila como una estrategia legítima para el cambio social y como un mecanismo alternativo del propio Estado Constitucional, para satisfacer las 
demandas relegadas por la ineficiencia del poder legislativo y de la administración".

A este respecto (Zagrebelsky 2002 p. 17) afirma que la dogmática constitucional debe ser como el líquido donde las sustancias que se vierten - los conceptosmantienen su individualidad y coexisten sin choques destructivos, aunque con ciertos movimientos de oscilación, y, en todo caso, si que jamás un solo componente pueda imponerse o eliminar a los demás.

Por otra parte respecto a las relaciones entre el gobierno y los jueces, el tema de tridivisión de poderes y su importancia en la concreción del funcionamiento de cualquier Estado se da a partir del respeto por las funciones y de una colaboración entre ellas para la consecución de los fines propios del Estado, y frente al problema de la efectividad de los derechos, se presenta la suplantación de las funciones del gobierno por parte de los órganos judiciales.

Respecto a la Corte Constitucional colombiana, genera un cambio respecto al paradigma en el Estado y pasamos a un Estado Constitucional donde la Corte juega un papel preponderante. 
La Corte Constitucional tiene la misión de guardiana de la integridad y supremacía de la Constitución, y por tanto es ella quien debe interpretar los derechos constitucionales.

Ante la ineficiencia política del Congreso y del Ejecutivo generadora de vacíos de poder, y que ponen en tela de juicio la garantía de los derechos fundamentales, se establece el Estado de Cosas Inconstitucional, que reclaman de la Corte una rápida y efectiva intervención, dando lugar a decisiones jurisprudenciales que pueden llegar a tener lineamientos importantes con tintes de orden político, y que dan origen a ideas de usurpación de funciones entre las ramas del poder público y vulneración al principio constitucional de separación de poderes.

El Estado Constitucional de Derecho, evoluciona a pasos gigantes, introduciendo innovaciones en la manera de entender el derecho; es así como la creación de principios, valores y derechos constitucionales que afectan la estructura de la norma jurídica, la institución del control de constitucionalidad de las leyes, tanto como la aplicabilidad de las normas constitucionales, provocan una manera diferente de concebir el derecho, y es así como estos pasos evolutivos convergen hacia lo que hoy los doctrinantes denominan el Neoconstitucionalismo, que para algunos encarna el activismo constititucional, el peligro al principio de seguridad jurídica, y la posible usurpación de funciones en el Estado Constitucional. 
Por esta razón es de vital importancia en este momento, que el Estado se concentre en la correcta formación y preparación de los abogados, jueces, magistrados y en ultimas a todos los llamados operadores jurídicos, teniendo en cuenta, que el papel que juegan al interior de la sociedad es cada vez de mayor impacto y relevancia, ya que de ellos depende ahora que la inseguridad jurídica y falta de certeza del derecho no se convierta en un problema jurídico a gran escala, generando crisis institucional.

Por otra parte, el Estado debe hacer un gran esfuerzo, para el cumplimiento de las promesas constitucionales y la eficacia de de todos sus postulados, contribuyendo de esta forma a evitar que la rama judicial se salga de sus competencias, con el objeto de hacer cumplir la constitución, en los casos en los que la inoperancia del Estado lo amerita.

La realidad enfrenta siempre cambios, trayendo consigo nuevas realidades. La democracia, debe ser el principio prevalente al cual respondan las actuaciones de los organismos del poder ya que son precisamente los desniveles de poder, los que en ultimas activan la justicia constitucional.

\section{REFERENCIAS:}


ARAGÓN (1997). El Juez Ordinario entre Legalidad y Constitucionalidad. Colombia. Ed. U. Externado

BERNAL (2005), El Derecho de los Derechos. Ed. Universidad Externado de Colombia.

BERNAL (2007) El Neoconstitucionalismo a Debate. Instituto de estudios constiucionales. Ed. Universidad Externado de Colombia.

COMANDUCCI, (2003). Formas de (Neo) constitucionalismo. Un análisis metateórico. Edición de Miguel Carbonell. Editorial Trotta.

FERRAJOLI (2003). Pasado y Futuro del Estado de Derecho. Ed. de Miguel Carbonell. Editorial Trotta.

GARCIA (2003), Teoría del derecho en tiempos de constitucionalismo. Edición de Miguel Carbonell. Editorial Trotta.

GARCIA FIGUEROA, Alonso. Principios y Positivismo Jurídico. El no positivismo principialista en la teorías de de Dworkin y Alexy.

GUASTINI, (2003). La "constitucionalización" del ordenamiento jurídico: el caso italiano. Edición de Miguel Carbonell. Editorial Trotta . 
MORELLI (1997). La Corte Constitucional ¿Un Legislador Complementario?. Ed. U Externado. Colombia

MORESO, José Juan. Comanducci sobre Neoconstitucionalismo. Trabajo presentado como una réplica a la contribución de Paolo Comanducci al seminario Albert Calsamiglia, que tuvo lugar en la Universidad de Pompeu Fabra (Barcelona) en Febrero de 2003.

LOPEZ MEDINA, Diego Eduardo. El derecho de los jueces ed. Uniandes 2000.

SCHMITT (1983). La defensa de la Constitución, Madrid, Tecnos.

SAVIGNY (2004) Metodología jurídica, Buenos Aires: Valletta.

UPRIMNY (2004). Abierta pero no neutra, Constitución y modelo económico en Colombia", en Memorias del conservatorio «Diálogo entre abogados y economistas sobre la constitución en el aspecto económico», Bogotá, Ministerio de Hacienda y Crédito Público, ISBN 978-958-926-638-0, pp.1128.

ZAGREBELSKY (2002), El Derecho Dúctil. Ley Derechos y Justicia. Trotta. Madrid. 